\title{
Comments to the Paper "Occlusal Interferences: How Can This Concept Influence the Clinical Practice?"
}

In the aforementioned paper ${ }^{1}$ the authors performed a brief review about "the role of occlusal interferences on the development and progression of temporomandibular dysfunction (TMD) and postural disorders". This review shows a clear bias with several articles favoring the cited relationships (Dental Occlusion, Temporomandibular Disorders and Postural Dysfunction), whereas relevant papers that question these same relationships ${ }^{2-17}$ were ignored. Because of this bias the statements that "occlusal interferences can play an important role in the development of TMDs" and "the relevance of the occlusal adjustment on the treatment of TMDs should be reevaluated", seem not based in actual scientific literature, but rather only reflect the authors' personal point of view.

Reynaldo Leite Martins Júnior

Brazil

\section{REFERENCES}

1. Lima AF, Cavalcanti AN, Martins LR, Marchi GM. Occlusal interferences: how can this concept influence the clinical practice? Eur J Dent 2010;4:487-491.

2. Obrez A, Stohler CS. Jaw muscle pain and its effect on gothic arch tracings. J Prosthet Dent 1996;75:393-398.

3. Yatani H, Minakuchi H, Matsuka Y, Fujisawa T, Yamashita $A$. The long-term effect of occlusal therapy on selfadministered treatment outcomes of TMD. J Orofac Pain 1998; 12:75-88.

4. Tsukiyama Y, Baba K, Clark GT. An evidence-based assessment of occlusal adjustment as a treatment for temporomandibular disorders. J Prosthet Dent 2001;86:57-66.

5. Fujii T. The relationship between the occlusal interference side and the symptomatic side in temporomandibular disorders. J Oral Rehabil 2003;30:295-300.
6. Koh H, Robinson PG. Occlusal adjustment for treating and preventing temporomandibular joint disorders. Cochrane Database Syst Rev 2003;(1):CD003812.

7. Forssell H, Kalso E. Application of principles of evidencebased medicine to occlusal treatment for temporomandibular disorders: are there lessons to be learned? J Orofac Pain 2004;18:9-22; discussion 23-32. Stohler CS. Taking stock: from chasing occlusal contacts to vulnerability alleles. Orthod Craniofac Res 2004;7:157-161.

8. Gesch D, Bernhardt O, Alte D, Kocher T, John U, Hensel E. Malocclusions and clinical signs or subjective symptoms of temporomandibular disorders (TMD) in adults. Results of the population-based study of health in Pomerania (SHIP). J Orofac Orthop 2004;65:88-103.

9. Gesch D, Bernhardt O, Mack F, John U, Kocher T, Alte D. Association of malocclusion and functional occlusion with subjective symptoms of TMD in adults: results of the study of health in Pomerania (SHIP). Angle Orthod 2005;75:183190.

10. Michelotti A, Farella M, Gallo LM, Veltri A, Palla S, Martina R. Effect of occlusal interference on habitual activity of human masseter. J Dent Res 2005;84:644-648.

11. Michelotti A, Farella M, Steenks MH, Gallo LM, Palla S. No effect of experimental occlusal interferences on pressure pain thresholds of the masseter and temporalis muscles in healthy women. Eur J Oral Sci 2006;114:167-170.

12. Perinetti G. Temporomandibular disorders do not correlate with detectable alterations in body posture. J Contemp Dent Pract 2007;8:60-67.

13. Michelotti A, Farella M, Buonocore G, Pellegrino G, Piergentili C, Martina R. Is unilateral posterior crossbite associated with leg length inequality? Eur J Orthod 2007;29:622626.

14. Türp JC, Greene CS, Strub JR. Dental occlusion: a critical reflection on past, present and future concepts. J Oral Rehabil 2008;35:446-453. 
15. Chiappe G, Fantoni F, Landi N, Biondi K, Bosco M. Clinical value of 12 occlusal features for the prediction of disc displacement with reduction (RDC/TMD Axis I group Ila). J Oral Rehabil 2009;36:322-329.

16. Bereiter DA, Okamoto K, Tashiro A, Nixdorf DR. A comment on experimental occlusal interference induces long-term masticatory muscle hyperalgesia in rats by Cao et al. Pain 2010;148:519.

17. Perinetti G, Contardo L, Biasati AS, Perdoni L, Castaldo A. Dental malocclusion and body posture in young subjects: a multiple regression study. Clinics (Sao Paulo) 2010;65:689695.

\section{Author's response}

First, we would like to thank the comments regarding our manuscript. We feel that this type of discussion is helpful in scientific setting. However, we have several points to argue. One of them is the studies mentioned by the commentaries. Some manuscripts are not related to the occlusal interferences as a main problem, but instead, linked to a malocclusion in specific population or jaw muscle pain, points that are related to the Temporo-Mandibular Dysfunctions (TMDs).1,2 Another mentioned study made conclusions using few patients in its evaluation, which can restrict the results obtained by the manuscript. ${ }^{3}$ Additionally, we excluded from our review comments respect to others studies ${ }^{4}$ because, this information represents personal point of view, and could not be cited as scientific data.

We, at any moment, assure the fact that the occlusal interferences are the main etiologic factor of the TMDs, but as shown by scientific data, which the occlusal interferences can be involved in some TMDs cases. As the commentary's authors cited, and the brief review conclude "the relevance of the occlusal adjustment on the treatment of TMDs should be reevaluated". With this, the authors would lead the readers to evaluate all factors related to TMDs, including the occlusal interferences.

One fact that should be considered is that several articles were presented, ${ }^{5-18}$ showed through accurate scientific methods, that occlusal interferences can be involved in the TMD, at least, as a risk factor, clearly demonstrating that our conclusions are based on actual scientific literature, not only reflecting the authors' personal point of view.

Finally, the article "Occlusal Interferences: How Can This Concept Influence the Clinical Practice?" was presented as a brief review and not as a systematic review, and it is true that several reports were omitted, since the literature about Temporo-Mandibular Dysfunctions is extensive and, like cited in the manuscript, a controversial issue.

\section{Adriano Fonseca Lima} Brazil

\section{REFERENCES}

1. Gesch D, Bernhardt O, Kocher T, John U, Hensel E, Alte D. Association of malocclusion and functional occlusion with signs of temporomandibular disorders in adults: results of the population-based study of health in Pomerania. Angle Orthod 2004;74:512-520.

2. Obrez A, Stohler CS. Jaw muscle pain and its effect on gothic arch tracings. J Prosthet Dent 1996;75:393-398.

3. Michelotti A, Farella M, Gallo LM, Veltri A, Palla S, Martina R. Effect of occlusal interference on habitual activity of human masseter. J Dent Res 2005;84:644-648.

4. Bereiter DA, Okamoto K, Tashiro A, Nixdorf DR. A comment on experimental occlusal interference induces long-term masticatory muscle hyperalgesia in rats by Cao et al. Pain 2010;148:519; author reply 519-520.

5. Le Bell Y, Jamsa T, Korri S, Niemi PM, Alanen P. Effect of artificial occlusal interferences depends on previous experience of temporomandibular disorders. Acta Odontol Scand 2002;60:219-222.

6. Le Bell Y, Niemi PM, Jamsa T, Kylmala M, Alanen P. Subjective reactions to intervention with artificial interferences in subjects with and without a history of temporomandibular disorders. Acta Odontol Scand 2006;64:59-63.

7. Niemi PM, Le Bell Y, Kylmala M, Jamsa T, Alanen P. Psychological factors and responses to artificial interferences in subjects with and without a history of temporomandibular disorders. Acta Odontol Scand 2006;64:300-305.

8. Karppinen K, Eklund S, Suoninen E, Eskelin M, Kirveskari P. Adjustment of dental occlusion in treatment of chronic cervicobrachial pain and headache. J Oral Rehabil 1999;26:715721.

9. Kirveskari P, Alanen P. Occlusal variables are only moderately useful in the diagnosis of temporomandibular disorder. J Prosthet Dent 2000;84:114-115.

10. Kirveskari $P$, Jamsa T, Alanen P. Occlusal adjustment and the incidence of demand for temporomandibular disorder treatment. J Prosthet Dent 1998;79:433-438. 
11. Forssell H, Kirveskari P, Kangasniemi P. Effect of occlusal adjustment on mandibular dysfunction. A double-blind study. Acta Odontol Scand 1986;44:63-69.

12. Forssell H, Kirveskari P, Kangasniemi P. Response to occlusal treatment in headache patients previously treated by mock occlusal adjustment. Acta Odontol Scand 1987;45:7780 .

13. Wenneberg B, Nystrom T, Carlsson GE. Occlusal equilibration and other stomatognathic treatment in patients with mandibular dysfunction and headache. J Prosthet Dent 1988;59:478-483.

14. Gangloff P, Louis JP, Perrin PP. Dental occlusion modifies gaze and posture stabilization in human subjects. Neurosci Lett 2000;293:203-206.

15. Bracco P, Deregibus A, Piscetta R. Effects of different jaw relations on postural stability in human subjects. Neurosci Lett 2004;356:228-230.

16. Cuccia A, Caradonna C. The relationship between the stomatognathic system and body posture. Clinics 2009;64:6166.

17. Kirveskari $P$, Jamsa T. Health risk from occlusal interferences in females. Eur J Orthod 2009;31:490-495.

18. Cao Y, Xie QF, Li K, Light AR, Fu KY. Experimental occlusal interference induces long-term masticatory muscle hyperalgesia in rats. Pain 2009;144:287-293. 